R. Shirley, J. Akroyd, L. A. Miller , O. R. Inderwildi, U. Riedel, M. Kraft, theoretical insights into the surface growth of rutile $\mathrm{TiO}_{2}$, Combustion and Flame, 158 (2011) 1868-1876.

The original publication is available at www.elsevier.com

http://dx.doi.org/10.1016/j.combustflame.2011.06.007 


\title{
Theoretical insights into the surface growth of rutile $\mathrm{TiO}_{2}$
}

\author{
Raphael Shirley ${ }^{\mathrm{a}}$, Jethro Akroyd ${ }^{\mathrm{a}}$, Luke A. Miller ${ }^{\mathrm{a}}$, Oliver R. Inderwildi ${ }^{\mathrm{c}}$, \\ Uwe Riedel $^{\mathrm{b}}$, Markus Kraft ${ }^{\mathrm{a}, *}$ \\ ${ }^{a}$ Department of Chemical Engineering and Biotechnology, University of Cambridge, New \\ Museums Site, Cambridge, UK \\ ${ }^{b}$ Institut für Verbrennungstechnik, Deutsches Zentrum für Luft und Raumfahrt, \\ Universität Stuttgart, Pfaffenwaldring 38-40, 70569 Stuttgart, Germany \\ ${ }^{c}$ Smith School of Enterprise and the Environment, University of Oxford, Oxford, UK
}

\begin{abstract}
Adsorption of $\mathrm{TiCl}_{4}$ molecules on the reduced [1 10 ] surface of $\mathrm{TiO}_{2}$ is investigated using density functional theory with plane wave basis sets and pseudo-potentials. Adsorption energies and barriers are calculated and discussed. The rate of this adsorption process is calculated using transition state theory with estimated vibrational frequencies. Derived activation energies for $\mathrm{TiCl}_{4}$ adsorption are associated with significant error bounds, which encapsulate the experimental activation energy for the overall growth process. Quantitative predictions of the rate can not be made based on these theoretical calculations alone, due to sensitive dependence on the vibrational frequencies. Building on the theoretical work presented here and previous experimental results a new kinetic model is constructed consisting of a $\mathrm{TiCl}_{4}$ adsorption step followed by a secondary reaction with gaseous $\mathrm{O}_{2}$. Simulations of a plug flow reactor are used to fit the kinetic constants for the rate limiting adsorption step. Unlike the previous phenomenological models, this new Eley-Rideal model is under the theoretical limit at all conditions and contains a physically motivated dependence on gas phase concentrations.
\end{abstract}

Keywords: Surface growth, Titanium dioxide, Titanium tetrachloride

\footnotetext{
*Corresponding author

Email address: mk306@cam.ac.uk (Markus Kraft)
} 


\section{Introduction}

Titanium dioxide $\left(\mathrm{TiO}_{2}\right)$ is widely used as a pigment, as a catalyst support, and as a photocatalyst. The combustion of titanium tetrachloride $\left(\mathrm{TiCl}_{4}\right)$ to synthesise $\mathrm{TiO}_{2}$ nanoparticles is a multi-million tonne per year industrial process [1]. Typical operating conditions involve purified $\mathrm{TiCl}_{4}$ being oxidised at high temperatures (1500-2000 K) in a pure oxygen plasma or flame to produce $\mathrm{TiO}_{2}$ particles $[2,3] . \mathrm{TiO}_{2}$ crystallises in three different forms: rutile, anatase and brookite. Rutile is tetragonal and fully described by three parameters: $a, c$ and, $u$. The parameters $a$ and $c$ are shown in Figure 1, $u$ defines the fractional coordinate of the $\mathrm{O}$ atom.

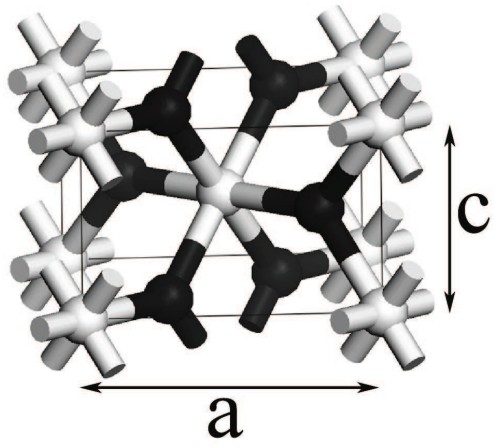

(a) Rutile unit cell.

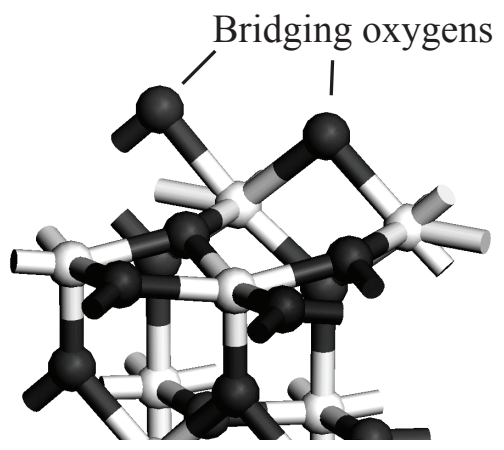

(b) Rutile 110 surface.

Figure 1: Unit cell of rutile $\mathrm{TiO}_{2}$ and the stoichiometric [1 110$]$ surface. Titanium atoms are white, oxygen atoms are black. The oxygen atoms at the top of (b) we call bridging oxygen atoms. When there is no oxygen atom present we refer to the site as an oxygen vacancy.

The majority of titania is produced in the rutile form because it is the most stable and has the highest refractive index. These qualities are both crucial for its application as a pigment; gaining the ability to control them is a major technological challenge. The chloride process is well established but we still lack a full understanding of how particles incept and grow. Controlling particle size distributions and other important particle properties depends on a fundamental understanding of particle growth.

This work is concerned with surface growth, the rate of which is not well understood. Simulations conducted so far $[4,5,6,7,8]$, have relied on the first-order rate expression measured by Ghoshtagore [9] at 673-1020 K: 


$$
\frac{\mathrm{d} N_{\mathrm{TiO}_{2}}}{\mathrm{~d} t}=A\left[\mathrm{TiCl}_{4}\right] 4.9 \times 10^{3} \mathrm{~cm} \mathrm{~s}^{-1} \times \exp \left(\frac{-74.8 \mathrm{~kJ} / \mathrm{mol}}{k_{\mathrm{B}} T}\right)
$$

where $N_{\mathrm{TiO}_{2}}$ is the amount of $\mathrm{TiO}_{2}$ deposited, $A$ is the surface area, and $\left[\mathrm{TiCl}_{4}\right]$ is the concentration of gas phase $\mathrm{TiCl}_{4}$. However, recent work has cast doubt on this rate [10], which is often applied well beyond the conditions at which it was attained. Given the importance of surface growth to the overall synthesis process it is imperative to improve our estimate for the overall rate. Competition between gas phase and surface reaction in the particle formation process is critical to particle properties [4]; any modelling investigation is dependent on accurate rates. Theoretical investigations have suggested that surface growth may be important in phase determination [11]. Furthermore, additives will likely have an impact on surface growth rates $[12,13,14]$ and a detailed molecular model of surface reactions is required to investigate this.

The major experimental conclusion of Ghoshtagore [9] is that an EleyRideal model is operating with atomic oxygen as the chemisorbed species and molecular $\mathrm{TiCl}_{4}$ colliding on the surface from the gas phase. However, the more recent work by Smith et al. [15] claims that the surface can grow by reaction of gaseous $\mathrm{O}_{2}$ with the reduced surface. They provide useful information about the $\mathrm{O}_{2}$ adsorption step, arguing that it is reaction of molecular oxygen in the gas phase with $\mathrm{Ti}^{3+}$ ions on the surface that is the rate limiting step. The latter work does not suggest a mechanism for taking $\mathrm{TiCl}_{4}$ out of the gas and is concerned with conditions that are different to those in an industrial reactor given that no $\mathrm{TiCl}_{4}$ is present. Figure 2 shows the different conditions used in experiments and industry, and highlights the need for a versatile surface growth model.

The best investigated surface of $\mathrm{TiO}_{2}$ is [1 10$]$, a full review which is given in Diebold [16]. This is partly because it is the most stable surface and therefore has the largest area on the minimum energy crystal [17]. There are fewer investigations into the other surfaces but key processes may be similar across all faces. The adsorption of $\mathrm{H}_{2} \mathrm{O}, \mathrm{CO}$ and other species onto this surface has been investigated using Density Functional Theory (DFT) as it is applied in this work $[18,19,20]$.

$\mathrm{Cl}$ adsorption and desorption on [1 110$]$ has been investigated theoretically using DFT [21]. This study was a first attempt at understanding the overall surface growth process. It mentions the importance of $\mathrm{TiCl}_{4}$ adsorption but does not investigate it. Since the rate has been found to be first order with 


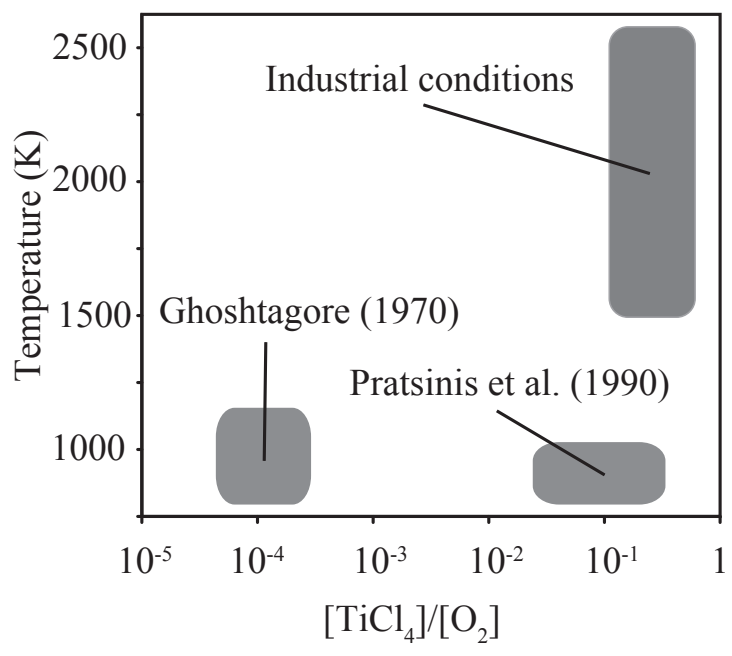

Figure 2: The work is motivated by concern over the application of the experimentally measured surface growth rates of Ghoshtagore [9] to industrial operating conditions, where it has been applied in previous models.

respect to $\mathrm{TiCl}_{4}$ concentration [9], and since this species is the most abundant Ti species at industrial temperatures, its adsorption is likely to be a critical process.

The first aim of this work is to investigate the atomistic processes involved in $\mathrm{TiCl}_{4}$ adsorption. This will allow us to determine the rough form any kinetic model should take. Comparisons will be made between theoretical rates in limiting cases in order to test current assumptions about surface growth. The second aim is to construct a kinetic model for surface growth. Simulations of particle formation and growth will be conducted using the moment method with interpolative closure [22], and a simplified particle population balance model, which assumes coalescent aggregation. These simulations will be used to compare the new model to experiment and to optimise surface growth rates that are consistent with both the experiment data and the other components of the model. This process is a first attempt to produce order of magnitude estimates for relative rates. It will not yield accurate values for parameters but will highlight areas where understanding is most lacking. This will allow us to provide a kinetic model that is motivated by an understanding of the atomistic processes involved, and capable of reproducing 
experimentally observed rates. The availability of multiscale models where each process has been validated in this way will facilitate future detailed particle simulations [23, 24], and simulations of nanoparticle formation in reacting flow $[25,26,27,28]$.

\section{Computational method}

This section summarises the theoretical tools used in the paper and details the convergence studies conducted in order to find suitable settings for the calculations. The CASTEP [29] software package is used for all the atomistic simulations. This uses pseudo-potentials and plane wave basis sets. The calculations are performed using the Perdew-Burke-Ernzerhof (PBE) [30] Generalised Gradient Approximation (GGA) functional. This functional has recently been shown to successfully reproduce bond lengths and energies [11]. Vanderbilt ultra-soft pseudo-potentials [31] are used to represent the core electrons.

\subsection{General parameters}

This section describes convergence studies with respect to the key calculation parameters; basis set size, and k-point spacing. All calculations use a basis set cutoff energy of $400 \mathrm{eV}$ which agrees with values found in the literature for similar systems [32]. A cutoff of $400 \mathrm{eV}$ was chosen after a convergence study with respect to surface energies, where errors due to basis set truncation were converged to $<0.01 \mathrm{eV}$. A $4 \times 4 \times 1$ Monkhorst-Pack grid [33] is used to derive a uniform set of irreducible k-points in reciprocal space. For transferability between systems of varying size, we refer to the $\mathbf{k}$-point spacing, which is found to be converged for $\mathrm{TiO}_{2}$ surface systems at a value of $\leq 0.04 \AA^{-1}$ in all spatial directions.

Spin-polarized calculations are used throughout. All the structures investigated changed only slightly when separately optimised for singlet and triplet states. The difference in energy between the optimised geometries at both spin states was uniformly $<0.01 \mathrm{eV}$.

\subsection{Boundary conditions}

We use a $\mathrm{Ti}_{24} \mathrm{O}_{48}$ periodic supercell with a $15 \AA$ vacuum slab and six $\mathrm{TiO}_{2}$ layers. Figure 3 shows convergence of surface energy with respect to number of layers. We are converged in terms of absolute energies to within $0.05 \mathrm{~J} \mathrm{~m}^{-2}$, which is sufficient for the energy differences we are calculating. Previous 
studies have restrained lower atoms in order to enforce the bulk geometry, however this leads to a strained cell and could introduce errors in surface energies. We allow all atoms to relax fully. There is some disagreement in the literature regarding the appropriate action here, with Kiejna et al. [32] recommending full relaxation of the outer surface layers and Hameeuw et al. [34] doing the opposite. All the convergence criteria used here are in broad agreement with the recommendations of Kiejna et al. [32].

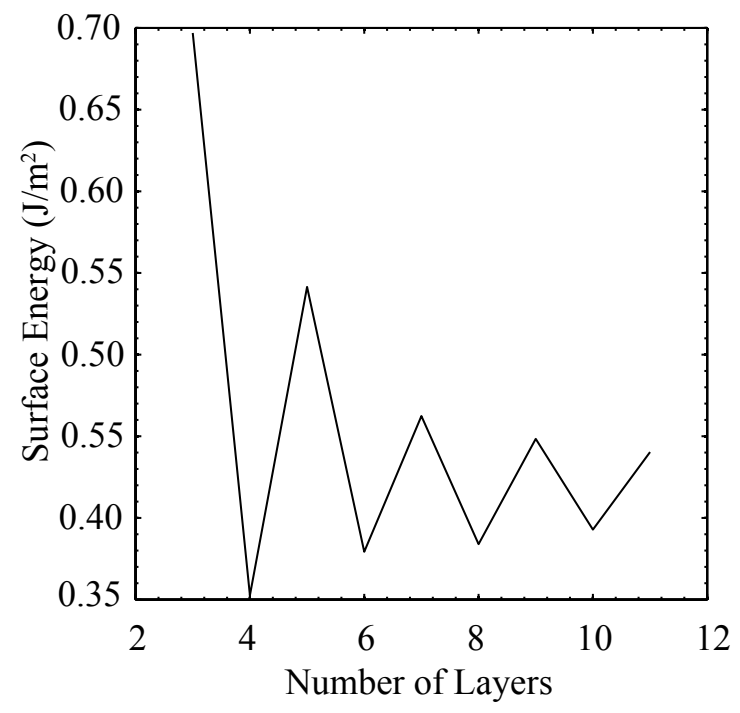

Figure 3: The calculated surface energy as a function of number of layers. The graph oscillates due to alternating alignment and non-alignment of bridging oxygens. It is possible to estimate the converged value based on only a small number of calculations on smaller films. We are interested in relative values which show weaker dependence on the number of layers.

The largest source of error is probably due to lateral interaction of $\mathrm{TiCl}_{4}$ molecules with their image in the neighboring supercell. Figure 4 shows the interaction energy of isolated $\mathrm{TiCl}_{4}$ molecules with respect to separation. Equation 2 can be used to calculate lateral interaction energy using the data presented in Figure 4.

$$
E_{\text {lat }}=\sum_{m} c_{m} V_{m},
$$


where $c_{m}$ is the number of each interaction type $m$, and $V_{m}$ is the energy of the interaction. Each adsorbed $\mathrm{TiCl}_{4}$ effectively interacts with four adjacent mirror images, two in one direction and two in the other. The total of these four lateral interactions is $(2 \times 2.7+2 \times 3.1) \mathrm{kJ} / \mathrm{mol}$, summing to $\approx+12 \mathrm{~kJ} / \mathrm{mol}$. It is difficult to ascertain the errors this will introduce to the transition state and adsorption energies. These errors are likely to be systematic and it is possible that lateral interactions will cancel out when calculating energy differences.

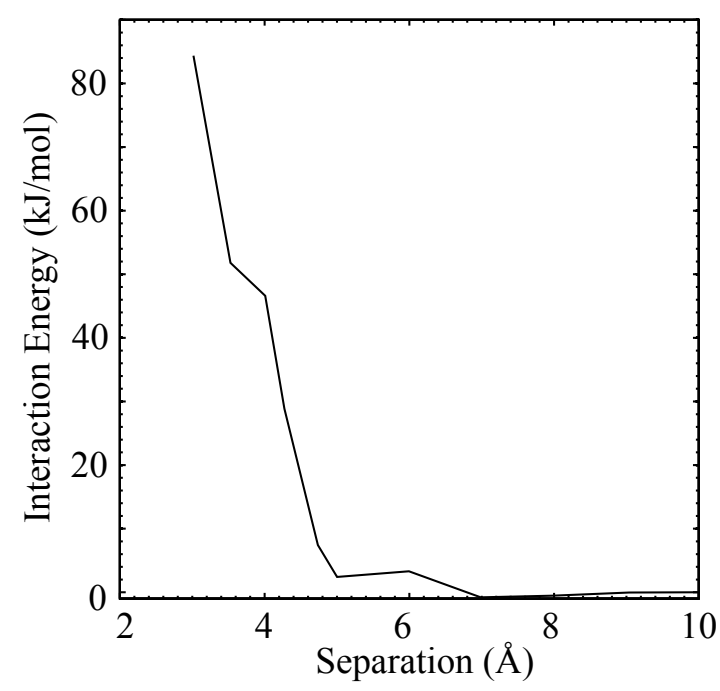

Figure 4: Interaction energy between two $\mathrm{TiCl}_{4}$ molecules in a large cell as a function of Ti atom separation from single point calculations. The supercell sizes used here to calculate adsorption energies correspond to lateral interaction energies of $2.7 \mathrm{~kJ} / \mathrm{mol}$ and $3.1 \mathrm{~kJ} / \mathrm{mol}$ in the two respective directions. Lateral interactions are probably the largest source of error.

\section{Density functional theory investigations}

This section describes investigations in to possible adsorbed structures for $\mathrm{TiCl}_{4}$, and calculations of the energetics and rate for $\mathrm{TiCl}_{4}$ adsorption on to an oxygen vacancy. The aim of this section is to investigate two possible 
hypotheses; that oxygen vacancies are the principle reactive site and that adsorption of $\mathrm{TiCl}_{4}$ on to them is the rate limiting step.

These hypotheses are made based on some results from the literature. Oxygen vacancies are one of the most common defect sites on rutile [1 110$]$ [35]. Many people have suggested they are likely to be important reactive sites [36, 21, 37]. Previous work reports that oxygen coverage is a crucial factor for surface growth $[21,8]$. More generally, it is widely known that the reactivity of any oxide surface depends on the extent to which surface ions are coordination unsaturated [38].

\subsection{The structure of adsorbed $\mathrm{TiCl}_{4}$}

We investigated possible adsorbed states by placing $\mathrm{TiCl}_{4}$ in various configurations around bridging oxygen atoms and vacancy sites, and then optimising the geometry with respect to total energy for the two lowest spin states. Figure 5 shows the only structure for adsorbed $\mathrm{TiCl}_{4}$ that we found. All the initial configurations we tried either optimised into this chemisorbed state, moved away from the surface, or failed to converge. We could not find a local minimum for $\mathrm{TiCl}_{4}$ on a bridging oxygen.

\subsection{The energetics and kinetics of $\mathrm{TiCl}_{4}$ adsorption}

The DFT simulations presented above indicate that vacancies may be a preferential adsorption site. We now investigate the potential energy surface for a gas phase $\mathrm{TiCl}_{4}$ molecule approaching and adsorbing at one of these vacancy sites. The results of these calculations are used with transition state theory to investigate some limiting cases in order to put bounds on the Arrhenius parameters of this process in an attempt to falsify the hypothesis that it is the rate limiting step.

\subsubsection{Adsorption energy}

The adsorption energy is calculated using,

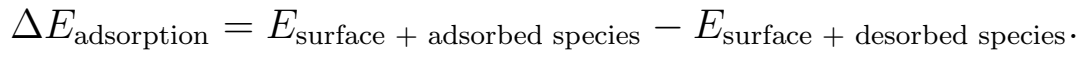

The adsorption energy from this calculation is $-117 \mathrm{~kJ} / \mathrm{mol}$. If lateral interaction energies are similar in the two right hand terms of Equation 3 there will be some cancelation of lateral interaction energies. This adsorption process is significantly exothermic. Consider that the initial decomposition 


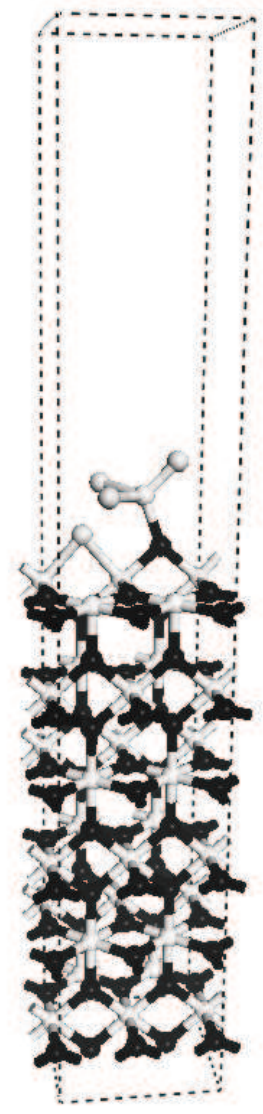

(a) One supercell.

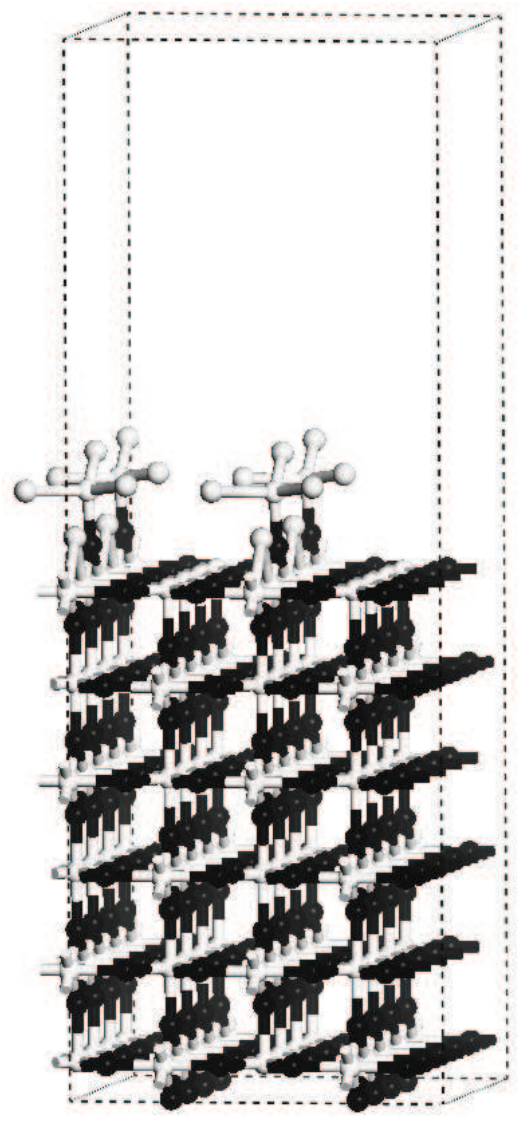

(b) Expanded view.

Figure 5: Optimised adsorbate structure shown on a 6 layer supercell. A copy of the optimised structure with an expanded view is also shown to demonstrate the proximity of adjacent adsorbed $\mathrm{TiCl}_{4}$ molecules. Oxygen atoms are black, titanium atoms are white. The $\mathrm{TiCl}_{4}$ molecule atop the surface is all white. 
of $\mathrm{TiCl}_{4}$ as measured by Herzler and Roth [39] is endothermic by $387 \mathrm{~kJ} / \mathrm{mol}$ at $298 \mathrm{~K}$. Given that Pratsinis et al. [40] measures the overall activation energy as $88.8 \mathrm{~kJ} / \mathrm{mol}, \mathrm{TiCl}_{4}$ consumption is clearly auto-catalysed by surface growth.

\subsubsection{Energy barrier}

Energy barriers correspond to saddle points on the potential energy surface. Here, we use the approach of Govind et al. [41] to locate the saddle point involved in the adsorption of $\mathrm{TiCl}_{4}$ on to an oxygen vacancy. We perform a Linear Synchronous Transit (LST) maximisation followed by a Conjugate Gradient (CG) minimisation. The linear path is based on an initial optimised geometry of $\mathrm{TiCl}_{4}$ desorbed from the surface and a final geometry of it adsorbed as in Figure 5. Further refinement can be made by performing a Quadratic Synchronous Transit (QST) maximisation followed by a CG minimisation. At the end of each step the average force on nuclei indicates how far from the saddle point the geometry is.

The potential energy surface in these simulations is highly multimodal and finding the saddle point to high accuracy is challenging. Figure 6 shows the result of a single LST/CG step, which gives a barrier of $25 \mathrm{~kJ} / \mathrm{mol}$. Alternatively, a further QST/CG step locates a point on the potential energy surface at $43 \mathrm{~kJ} / \mathrm{mol}$. However, forces on the atoms after one LST/CG step are lower $(0.2 \mathrm{eV} / \AA)$ than after the subsequent QST/CG step $(0.4 \mathrm{eV} / \AA)$, indicating the point at $43 \mathrm{~kJ} / \mathrm{mol}$ is further from the saddle point where all forces are necessarily zero.

Forces on atoms are lower at the barrier at $25 \mathrm{~kJ} / \mathrm{mol}$, and we therefore recommend this value for the barrier but readers must be aware that the two values differ by $18 \mathrm{~kJ} / \mathrm{mol}$, and therefore the barrier of $25 \mathrm{~kJ} / \mathrm{mol}$ should be considered a rough estimate. This is taken into account in Table 1, where errors in the barrier are propagated through to the activation energy by investigating barriers of $5 \mathrm{~kJ} / \mathrm{mol}, 25 \mathrm{~kJ} / \mathrm{mol}$, and $45 \mathrm{~kJ} / \mathrm{mol}$. This energy barrier of $\mathrm{TiCl}_{4}$ adsorption on an oxygen vacancy, $25 \mathrm{~kJ} / \mathrm{mol}$, is a similar order of magnitude albeit lower than the overall, $74.8 \mathrm{~kJ} / \mathrm{mol}$, activation energy fitted by Ghoshtagore [9]. Note that when referring to observed/fitted Arrhenius models we speak of an 'activation energy', $E_{\mathrm{a}}$, and when referring to the physical barrier we use the term 'energy barrier', $E_{\mathrm{b}}$. A large part of the observed activation energy comes from the temperature dependence introduced by the partition functions in transition state theory and not from the actual energy barrier. We will now calculate the temperature dependence 


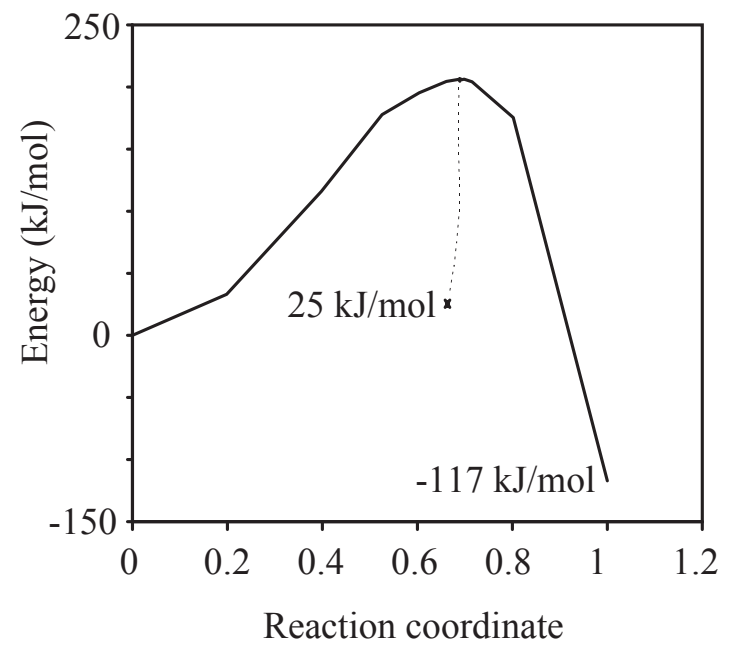

Figure 6: The energy as a function of reaction coordinate (fractional position along linear path). The main line shows the linear synchronous transit step. The dashed line from the peak of the linear step shows a conjugate gradient step which leads to a significant reduction in energy (from $207 \mathrm{~kJ} / \mathrm{mol}$ to $25 \mathrm{~kJ} / \mathrm{mol}$ ). The energy scale is defined such that the energy of the desorbed species is 0. Precise energies and geometries are available as CASTEP output files in the Supporting Information. 
of the overall rate in order to properly test compatibility with Ghoshtagore $[9]$.

\subsubsection{Adsorption rate}

Rates of adsorption can be estimated using classical transition state theory,

$$
k_{\mathrm{TST}}=\frac{k_{\mathrm{B}} T}{h} \frac{Q^{\ddagger}}{Q_{\mathrm{rot}} Q_{\mathrm{vib}}\left(Q_{\mathrm{trans}} / V\right)} \exp \left(\frac{-E_{\mathrm{b}}}{k_{\mathrm{B}} T}\right),
$$

where $Q^{\ddagger}$ is the partition function of the transition state, $Q_{\text {rot }} Q_{\text {vib }}\left(Q_{\text {trans }} / V\right)$ is the partition function of the gaseous species, composed of a rotational $\left(Q_{\mathrm{rot}}\right)$, vibrational $\left(Q_{\mathrm{vib}}\right)$, and translational $\left(Q_{\mathrm{trans}} / V\right)$ contribution, and $E_{\mathrm{b}}$ is the energy barrier to adsorption. The translational partition function is divided by the volume occupied by the molecule, $V$, in order to give the rate constant in terms of concentrations. When calculating $Q_{\text {vib }}$ we take the classical minimum as the zero of energy so that $E_{\mathrm{b}}$ does not require a zero point correction. If we assume that all the transition state modes are vibrations then $Q^{\ddagger}$ will have five more vibrational modes than $Q_{\text {vib }}$. In order to calculate predictive quantitative rates it might be necessary to consider rotations in the transition state but for the purposes of inspecting bounds on the Arrhenius parameters this assumption is sufficient. All of the partition functions are simple functions of temperature and can be found in any statistical mechanics text book [42].

The geometry of the transition state found in the previous section was not sufficiently optimised to give a single imaginary frequency. Despite this inaccuracy it is still possible to consider some limiting cases. If we estimate the new vibrational frequencies of the transition state by assuming they are all equal to the lowest frequency for any molecule investigated in West et al. [43] $\left(14.1 \mathrm{~cm}^{-1}\right)$, and assume the original molecular frequencies are unchanged, we can calculate an order of magnitude estimate for the rate. This approximation will not be accurate but it allows us to investigate the effect of frequencies on the kinetic parameters and find bounds for their values. This estimate will be an upper limit given that we use a low frequency for all the new modes. We calculate $k_{\mathrm{TST}}$ over the range $500-1600 \mathrm{~K}$ and fit an Arrhenius form $\left(k=A \exp \left(E_{a} / k_{\mathrm{B}} T\right)\right)$ to it. Figure 7 shows the calculated rate alongside the fitted rate given by Equation 5, 


$$
k_{\mathrm{TST}} \approx 3 \times 10^{13} \exp \left(\frac{60 \mathrm{~kJ} / \mathrm{mol}}{k_{\mathrm{B}} T}\right) \mathrm{cm}^{3} \mathrm{~mol}^{-1} \mathrm{~s}^{-1}
$$

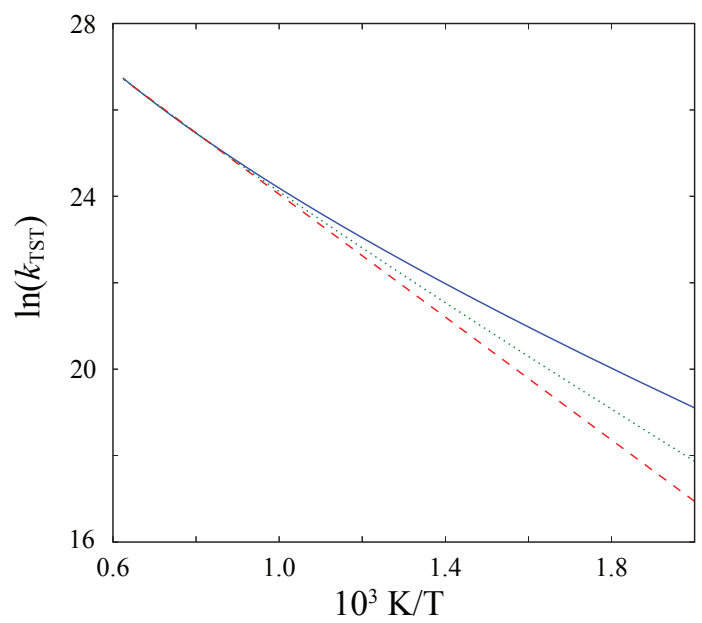

Figure 7: Arrhenius plot for the calculated rate of adsorption of $\mathrm{TiCl}_{4}$ on to a bridging oxygen vacancy using estimated frequencies for the transition state (solid blue line), which give an upper limit. The fitted Arrhenius form (dashed red line, $k=A \exp \left(E_{a} / k_{\mathrm{B}} T\right)$ ) is slightly improved by a modified Arrhenius form (dotted green line, $k=A T^{n} \exp \left(E_{a} / k_{\mathrm{B}} T\right)$ ).

If the same calculations are performed with the upper limit of the barrier, $45 \mathrm{~kJ} / \mathrm{mol}$, the corresponding activation energy is calculated as $80 \mathrm{~kJ} / \mathrm{mol}$. That is, the Ghoshtagore [9] experimental fit is within error bounds of our calculated activation energy.

The transition state found here was quite far from the surface (lowest molecule atom/surface atom separation $>3 \AA$ ). However, to be sure our estimated frequencies do not lead to drastically erroneous rates we considered the opposite extreme of high frequency modes. We computed rates by assuming the new vibrational modes take the value of the lowest frequency mode of $\mathrm{TiCl}_{4}\left(114 \mathrm{~cm}^{-1}\right)$. These bond stretches are significantly higher than modes associated with a physisorbed transition state. This indeed led to rates that were considerably slower. However, there was only moderate impact on the activation energy. Using all combinations of our limiting energy barriers and frequencies produced activation energies between $30 \mathrm{~kJ} / \mathrm{mol}$ 
and $80 \mathrm{~kJ} / \mathrm{mol}$. The frequencies have a large impact on the pre-exponential factor, but the activation energy is universally higher than the energy barrier by $\approx 30-35 \mathrm{~kJ} / \mathrm{mol}$ regardless of the estimated frequencies. The error in our calculated activation energy is therefore almost entirely due to the error in the energy barrier. Full details of the limiting values from these calculations are given in Table 1.

Table 1: Limiting values for the energy barrier and new transition state modes along with rates calculated using transition state theory. A characteristic rate constant is shown at $1000 \mathrm{~K}$ as are values for the Arrhenius parameters fitted over the temperature range 500-1600 K.

\begin{tabular}{|c|c|c|c|c|}
\hline \multirow[b]{2}{*}{$\begin{array}{l}f_{\text {est }} \\
\mathrm{cm}^{-1}\end{array}$} & \multirow[b]{2}{*}{$\begin{array}{c}E_{\mathrm{b}} \\
\mathrm{kJ} / \mathrm{mol}\end{array}$} & \multirow[b]{2}{*}{$\begin{array}{l}k_{\mathrm{TST}} \text { at } 1000 \mathrm{~K} \\
\mathrm{~cm}^{3} \mathrm{~mol}^{-1} \mathrm{~s}^{-1}\end{array}$} & \multicolumn{2}{|c|}{$k_{\mathrm{Arr}}=A \exp \left(-E_{\mathrm{a}} / k_{\mathrm{B}} T\right)$} \\
\hline & & & $\begin{array}{c}A \\
\mathrm{~cm}^{3} \mathrm{~mol}^{-1} \mathrm{~s}^{-1}\end{array}$ & $\begin{array}{c}E_{\mathrm{a}} \\
\mathrm{kJ} / \mathrm{mol}\end{array}$ \\
\hline 14.1 & 25 & $3 \times 10^{10}$ & $3 \times 10^{13}$ & 60 \\
\hline 14.1 & 45 & $3 \times 10^{9}$ & $4 \times 10^{13}$ & 80 \\
\hline 14.1 & 5 & $4 \times 10^{11}$ & $3 \times 10^{13}$ & 36 \\
\hline 114 & 25 & $9 \times 10^{5}$ & $1 \times 10^{9}$ & 60 \\
\hline 114 & 45 & $8 \times 10^{4}$ & $1 \times 10^{9}$ & 80 \\
\hline 114 & 5 & $1 \times 10^{7}$ & $8 \times 10^{8}$ & 37 \\
\hline
\end{tabular}

\subsection{Discussion and recommendations}

Until accurate vibrational frequencies can be found it is impossible to give quantitative values for the adsorption rate based on density functional theory calculations. However, calculated activation energies for the adsorption process investigated here are similar to the overall growth rate of Ghoshtagore [9]. After the $\mathrm{TiCl}_{4}$ adsorption step, the $\mathrm{Cl}$ atoms can desorb leaving $\mathrm{Ti}^{3+}$ ions which are free to enter the lattice and subsequently react with molecular oxygen for which Smith et al. [15] observe a $25 \mathrm{~kJ} / \mathrm{mol}$ barrier. This overall model for the process is in agreement with Rasmussen et al. [44] and Smith et al. [15] and would explain the activated growth process, as well as its order of magnitude compared to the collision limit. This description of surface growth will be used to construct a kinetic model in the next section. The major conclusions of this section are: 
- The adsorption energy for $\mathrm{TiCl}_{4}$ adsorbing on to an oxygen vacancy is $-117 \mathrm{~kJ} / \mathrm{mol}$ and the energy barrier is approximately $25 \mathrm{~kJ} / \mathrm{mol}$.

- Transition state theory calculations using limiting values for the vibrational frequencies indicate that the activation energy for the adsorption rate is $55 \pm 25 \mathrm{~kJ} / \mathrm{mol}$. We can not impose reasonable bounds on the pre-exponential factor based on these calculations.

- The large errors associated with the theoretically calculated activation energy, mean one cannot rule out the possibility that the adsorption of $\mathrm{TiCl}_{4}$ on to an oxygen vacancy site is the rate limiting step during the surface growth of $\mathrm{TiO}_{2}$.

\section{A kinetic model for surface growth}

In this section we build a kinetic model for surface growth based on experimental results from the literature and conclusions from the theoretical work presented in the previous section. There are two basic models for surface growth: Eley-Rideal and Langmuir-Hinshelwood. Ghoshtagore [9] rules out a Langmuir-Hinshelwood mechanism based on the observed temperature and concentration dependence. If the reaction proceeds via an Eley-Rideal model then there are two basic forms to consider: $\mathrm{O}_{2}$ adsorbs first and reacts with gas phase $\mathrm{TiCl}_{4}$, or $\mathrm{TiCl}_{4}$ adsorbs followed by reaction with $\mathrm{O}_{2}$.

Table 2 shows the Ghoshtagore [9] reaction scheme and two possible EleyRideal models that give similar rates. In the case of an infinitesimal surface where gas phase concentrations do not change, these processes enable a final state to be reached where surface coverage and $\mathrm{TiO}_{2}$ growth rate both reach a steady state. In order to check these models give similar $\mathrm{TiO}_{2}$ growth rates, Cantera [45] is used to integrate the corresponding ordinary differential equations and calculate this final rate. We define the quasi-steady state to be reached when the surface growth rate does not change by more than $10^{-5} \mu \mathrm{m} \mathrm{s}^{-1}$ over a period of $0.1 \mathrm{~ms}$. These quasi-steady state growth rates are frequently good approximations of actual growth rates due to the time scales concerned being considerably shorter than time scales involving variations of gas phase species concentrations [46].

Other gaseous intermediates could be important to growth. However, the initial thermal decomposition of $\mathrm{TiCl}_{4}$ is slow such that, in our reactor simulations (Section 4.2), over 99\% of Ti atoms in gaseous species are contained in $\mathrm{TiCl}_{4}$ at all times. Given the large gas phase concentrations of $\mathrm{TiCl}_{4}$, the 
Table 2: Simple reaction schemes that could be used to model growth. (g) and (s) signify gas and solid species respectively. $\mathrm{S}^{*}$ is used to represent a generic reactive surface site, $\mathrm{TiCl}_{4}{ }^{*}$ and $\mathrm{O}_{2}{ }^{*}$ represent adsorbed $\mathrm{TiCl}_{4}$ and $\mathrm{O}_{2}$. We assume $\mathrm{S}^{*}$ to be a bridging oxygen vacancy but it makes no difference to the macroscopic behaviour of the model. Rate constants are calculated based on $100 \%$ coverage of reactive sites and a surface site density of $9.43 \times 10^{-10} \mathrm{~mol} \mathrm{~cm}^{-2}$ from calculated lattice constants [11].

\begin{tabular}{|c|c|c|c|c|}
\hline \multirow[b]{2}{*}{$\#$} & \multirow[b]{2}{*}{ Reaction } & \multicolumn{3}{|c|}{$k=A T^{n} \exp \left(-E_{\mathrm{a}} / k_{\mathrm{B}} T\right)$} \\
\hline & & $\begin{array}{c}A \\
\mathrm{~cm}^{3} \mathrm{~mol}^{-1} \mathrm{~s}^{-1}\end{array}$ & $\begin{array}{l}n \\
-\end{array}$ & $\begin{array}{c}E_{\mathrm{a}} \\
\mathrm{kJ} / \mathrm{mol}\end{array}$ \\
\hline \multicolumn{5}{|c|}{ Model A: Ghoshtagore (zero order with respect to $\mathrm{O}_{2}$ ): } \\
\hline 1 & $\mathrm{TiCl}_{4}(\mathrm{~g})+\mathrm{S}^{*}+\mathrm{O}_{2}(\mathrm{~g}) \longrightarrow \mathrm{TiO}_{2}(\mathrm{~s})+2 \mathrm{Cl}_{2}(\mathrm{~g})+\mathrm{S}^{*}$ & $5.2 \times 10^{12}$ & 0 & 74.8 \\
\hline \multicolumn{5}{|c|}{ Model B: Eley-Rideal with $\mathrm{O}_{2}$ adsorption first: } \\
\hline 1 & $\mathrm{O}_{2}(\mathrm{~g})+\mathrm{S}^{*} \longrightarrow \mathrm{O}_{2}{ }^{*}$ & $6.8 \times 10^{11}$ & $\frac{1}{2}$ & 0.0 \\
\hline 2 & $\mathrm{O}_{2}{ }^{*}+\mathrm{TiCl}_{4}(\mathrm{~g}) \longrightarrow \mathrm{TiO}_{2}(\mathrm{~s})+\mathrm{S}^{*}+2 \mathrm{Cl}_{2}(\mathrm{~g})$ & $5.2 \times 10^{12}$ & 0 & 74.8 \\
\hline \multicolumn{5}{|c|}{ Model C: Eley-Rideal with $\mathrm{O}_{2}$ adsorption second: } \\
\hline 1 & $\mathrm{TiCl}_{4}(\mathrm{~g})+\mathrm{S}^{*} \longrightarrow \mathrm{TiCl}_{4}{ }^{*}$ & $5.2 \times 10^{12}$ & 0 & 74.8 \\
\hline 2 & $\mathrm{O}_{2}(\mathrm{~g})+\mathrm{TiCl}_{4}{ }^{*} \longrightarrow \mathrm{TiO}_{2}(\mathrm{~s})+2 \mathrm{Cl}_{2}(\mathrm{~g})+\mathrm{S}^{*}$ & $6.8 \times 10^{11}$ & $\frac{1}{2}$ & 0.0 \\
\hline
\end{tabular}


reaction of $\mathrm{TiCl}_{4}$ with the surface can not be ignored. First order dependence on $\mathrm{TiCl}_{4}$ concentration has been observed [9], and this must be reflected in the kinetic model, which can not be composed entirely of elementary reaction steps at this stage.

\subsection{Oxygen dependence}

Ghoshtagore [9] suggests that $\mathrm{O}_{2}$ adsorbs first based on some limiting case observations of the behaviour of the growth rate. He observed that at low $\mathrm{O}_{2}$ concentrations,

$$
\frac{\mathrm{d} N_{\mathrm{TiO}_{2}}}{\mathrm{~d} t} \propto A\left[\mathrm{TiCl}_{4}(\mathrm{~g})\right]\left[\mathrm{O}_{2}(\mathrm{~g})\right]^{1 / 2},
$$

but at high $\mathrm{O}_{2}$ concentrations,

$$
\frac{\mathrm{d} N_{\mathrm{TiO}_{2}}}{\mathrm{~d} t} \propto A\left[\mathrm{TiCl}_{4}(\mathrm{~g})\right]
$$

where $A$ is the surface area. We suggest an alternative interpretation of this observation; the process that removes $\mathrm{O}_{2}$ from the gas phase is fast compared to the corresponding process for $\mathrm{TiCl}_{4}$. One can construct two mechanisms which show the same behaviour, one with $\mathrm{O}_{2}$ chemisorption first followed by reaction with $\mathrm{TiCl}_{4}$ and another with the opposite ordering. Models $\mathrm{B}$ and $\mathrm{C}$ in Table 2 produce identical rates after they have been integrated to quasi-steady state constant coverages. When the oxygen adsorption rate is collision limited, models $\mathrm{B}$ and $\mathrm{C}$ behave identically to model A except at low $\mathrm{O}_{2}$ concentrations.

Ghoshtagore [9] defines a 'critical oxygen partial pressure', given by $p_{\mathrm{O}_{2 \text { crit }}} \propto$ $\left(p_{\mathrm{TiCl}_{4}}\right)^{3}$, below which there is half order oxygen dependence. Defining the oxygen dependence in this way is equivalent to giving the reaction an order of $-3 / 2$ with respect to $\mathrm{TiCl}_{4}$. Figure 8 shows the behaviour of both the original rate and that with his recommended oxygen dependence. The difference becomes large at industrial concentrations where the growth rate with half order $\mathrm{O}_{2}$ dependence becomes low. Extrapolation of this model to industrial conditions is not recommended.

This discussion has focused on what assumptions about the kinetic model can be made based on previous experimental investigations. The key results we take from these investigations are:

- Ghoshtagore [9] observes that surface growth shows half order dependence on oxygen concentration at low oxygen concentrations and is zero 


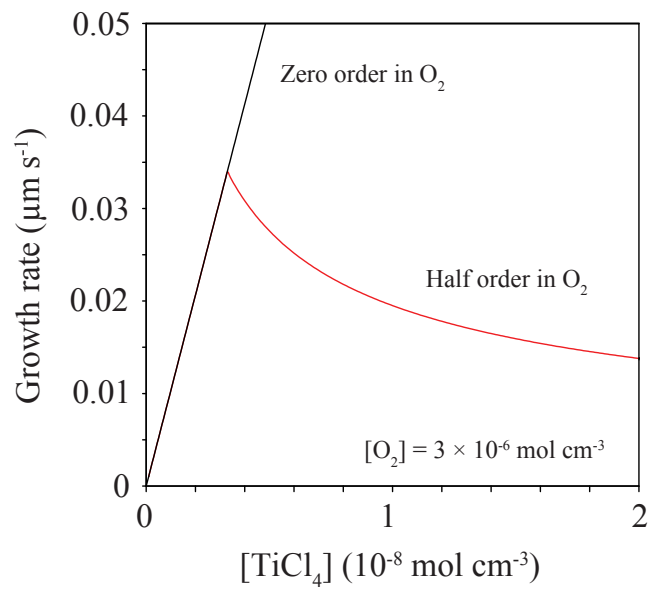

Figure 8: The surface growth rate as a function of $\left[\mathrm{TiCl}_{4}\right]$ for the Ghoshtagore [9] model. The black line shows how it has typically been applied with zero order oxygen dependence. The red line shows the modified rate with half order oxygen dependence. This is shown at relatively low concentrations of $\mathrm{TiCl}_{4}$. As $\left[\mathrm{TiCl}_{4}\right]$ increases the difference becomes large.

order in oxygen otherwise. From this result we argue that the process removing $\mathrm{O}_{2}$ from the gas phase is fast compared to the corresponding process for $\mathrm{TiCl}_{4}$.

- This oxygen dependence could be modelled by two equivalent EleyRideal models. It is well established that the surface is usually reduced [16], and Smith et al. [15] show that a reduced surface can grow by reaction with gaseous $\mathrm{O}_{2}$. This suggests a model with $\mathrm{TiCl}_{4}$ adsorption first.

- The mathematical form given by Ghoshtagore [9] for half order oxygen dependence can not be extrapolated beyond the low $\mathrm{TiCl}_{4}$ concentrations used in his experiments.

\subsection{Simulating a plug flow reactor}

The work presented in this paper was originally motivated by the failure of previous simulations [10] to reproduce the observations of Pratsinis et al. [40]. In this section, we investigate the impact of surface growth rates on 
these simulations using the moment method with interpolative closure to solve the population balance and couple it to the gas phase chemistry. This method is an inexpensive alternative to stochastic population balance solvers. It does not provide such detailed information about particles but has recently been shown to agree with stochastic simulations in terms of overall rates and low-order moments of the resulting size distributions [22].

The original Pratsinis et al. [40] investigation measured the reaction of $\left[\mathrm{O}_{2}\right] /\left[\mathrm{TiCl}_{4}\right]=5$ in argon (99\% by volume) in a tube, with an internal diameter of $1 / 8$ inch, heated to $973-1273 \mathrm{~K}$. Pratsinis et al. [40] calculate an effective rate constant for the overall oxidation kinetics of $\mathrm{TiCl}_{4}$ vapour,

$$
k_{\mathrm{eff}}=-\frac{\ln \left(C_{\mathrm{o}} / C_{\mathrm{i}}\right)}{t},
$$

assuming the reaction is first-order in $\mathrm{TiCl}_{4}$ with Arrhenius kinetics and where $C_{\mathrm{i}}$ and $C_{\mathrm{o}}$ are the measured inlet and outlet $\mathrm{TiCl}_{4}$ concentrations and $t$ is residence time in the isothermal zone of the reactor. This experiment was modelled using an imposed temperature profile taken from Pratsinis et al. [40, Figure 3].

For the purpose of fitting we adopt the simple one step surface growth model,

$$
\mathrm{S}^{*}+\mathrm{TiCl}_{4}(\mathrm{~g})+\mathrm{O}_{2}(\mathrm{~g}) \stackrel{k_{\mathrm{fit}}}{\longrightarrow} \mathrm{S}^{*}+\mathrm{TiO}_{2}(\mathrm{~s})+2 \mathrm{Cl}_{2}(\mathrm{~g}),
$$

with varying order, $m$, with respect to $\mathrm{O}_{2}(\mathrm{~g})$ :

$$
\frac{\mathrm{d}\left[\mathrm{TiO}_{2}(\mathrm{~s})\right]}{\mathrm{d} t}=k_{\mathrm{fit}}\left[\mathrm{S}^{*}\right]\left[\mathrm{TiCl}_{4}(\mathrm{~g})\right]\left[\mathrm{O}_{2}(\mathrm{~g})\right]^{m} .
$$

We use this phenomenological form so that reaction order with respect to oxygen can be investigated. Agreement could only be obtained by changing both the particle inception model and the surface growth rate. The inception model of West et al. [10] is based on the collision limited reaction of all titanium species containing two or more Ti atoms. This inception model was flawed in that reactions forming $\mathrm{Ti}_{3} \mathrm{O}_{x} \mathrm{Cl}_{y}$ species were not considered despite the fact that the smallest 'particle' in the population balance model was $\mathrm{Ti}_{4} \mathrm{O}_{8}$. We use a new inception model to give an upper limit on the inception rate. The new model is based on collision limited reactions of any pair of titanium oxychlorides as defined in Equation 11. 


$$
\begin{aligned}
& \mathrm{Ti}_{x_{1}} \mathrm{O}_{y_{1}} \mathrm{Cl}_{z_{1}}+\mathrm{Ti}_{x_{2}} \mathrm{O}_{y_{2}} \mathrm{Cl}_{z_{2}} \longrightarrow\left(x_{1}+x_{2}\right) \mathrm{TiO}_{2}(\mathrm{~s}) \\
& \quad+\left(\frac{y_{1}+y_{2}}{2}-x_{1}-x_{2}\right) \mathrm{O}_{2}+\left(\frac{z_{1}+z_{2}}{2}\right) \mathrm{Cl}_{2} \quad x, y, z \geq 1,
\end{aligned}
$$

where, the collision diameter is taken as $0.65 \mathrm{~nm}$. This is the next fastest inception model after allowing collision limited dimerisation of $\mathrm{TiCl}_{4}$ (which gives rates that are much too high), and gives some confidence that the fitted surface growth rate will not be an overestimate. Assuming coalescent aggregation will introduce some error. We observed negligible difference in the overall rate between the zero sintering (maximum surface area) simulations of West et al. [10] and comparable infinite sintering (minimum surface area) simulations conducted here. The impact of this assumption on the overall rate will be different with the new model but agreement with the original model gives some confidence in this assumption. Future work should investigate the possible impact of particle structure with the new inception and surface growth models.

\subsubsection{Parameter estimation and error analysis}

We used simulations of the plug flow reactor of Pratsinis et al. [40] to optimise the Arrhenius parameters of the overall surface growth rate of Equation 10 .

Figure 9 shows the behaviour of some of the older models along with the new modified and fitted model. The original model of West et al. [10] is barely distinguishable from simulations which ignore particle inception altogether; the consumption of $\mathrm{TiCl}_{4}$ is essentially negligible. Since the gas kinetics have been shown to compare favorably to short time-scale rapid compression machine experiments $[47,10]$ and are rate limited by well established experimental rates from shock tube experiments [39] we conclude that it is the particle processes that were too slow in the simulations of West et al. [10].

Achieving a good fit in Figure 9 was weakly dependent on both the temperature dependence of the surface growth rate and the order, $m$, with respect to oxygen. We investigated some limiting cases in an attempt to measure the errors associated with the fitting procedure. The values associated with these cases are shown in Table 3 . The table shows a pseudo rate constant $k_{\text {fit }}^{\prime}=k_{\text {fit }} \times\left[\mathrm{O}_{2}(\mathrm{~g})\right]^{m}$ at $1050 \mathrm{~K}$ for all of the fits and demonstrates a similar rate in all cases. It follows that we can only make statements regarding 


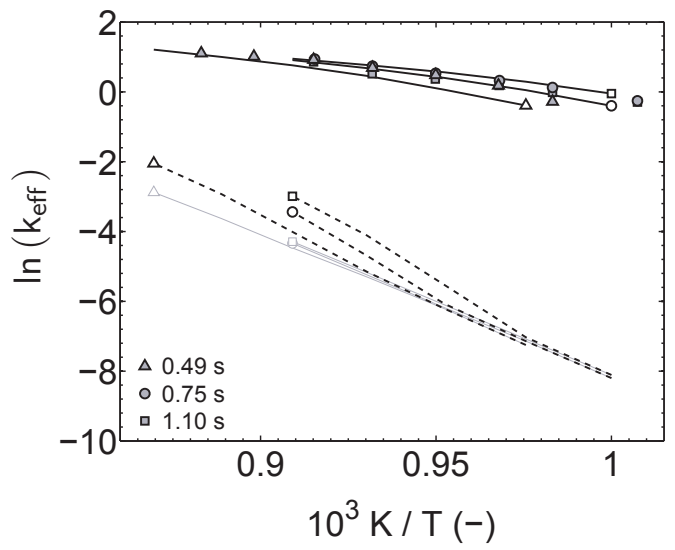

Figure 9: Arrhenius plot of the plug flow reactor results of Pratsinis et al. [40] (filled shapes). Also shown are simulations of the full particle formation process using a number of possible models. The light grey lines show simulation results using only the gas kinetic part of the model presented by West et al. [10]. The dashed lines show simulation using the full model presented by West et al. [10]. The solid lines passing through the experimental data points show simulations with inception processes based on Equation 11, and surface growth rate fitted to the Pratsinis et al. [40] data. 
ranges for the activation energy and pre-exponential factor. The pseudo rate constant for the Ghoshtagore [9] model at $1050 \mathrm{~K}$ is $1 \times 10^{9} \mathrm{~cm}^{3} \mathrm{~mol}^{-1} \mathrm{~s}^{-1}$, seven times smaller than the fitted rates.

Table 3: Limiting values for the Arrhenius parameters based on fitting the rate constant to Pratsinis et al. [40]. The order with respect to $\mathrm{O}_{2}$ concentration, $m$, has negligible impact on the fit. A pseudo rate constant $k_{\text {fit }}^{\prime}=k_{\text {fit }} \times\left[\mathrm{O}_{2}(\mathrm{~g})\right]^{m}$ is shown at $1050 \mathrm{~K}$ to demonstrate the equivalence of the reaction rates at a typical simulation temperature. Rate constants are calculated based on $100 \%$ coverage of reactive sites and a surface site density of $9.43 \times 10^{-10} \mathrm{~mol} \mathrm{~cm}^{-2}$.

\begin{tabular}{lcccc}
\hline & & \multicolumn{2}{c}{$k_{\text {fit }}=A \exp \left(-E_{\mathrm{a}} / k_{\mathrm{B}} T\right)$} & \\
\cline { 2 - 4 } Limiting case & $m$ & $\begin{array}{c}A \\
\left(\mathrm{~cm}^{3} \mathrm{~mol}^{-1}\right)^{m+1} \mathrm{~s}^{-1}\end{array}$ & $\begin{array}{c}E_{\mathrm{a}} \\
\mathrm{kJ} / \mathrm{mol}\end{array}$ & $\begin{array}{c}k_{\text {fit }}^{\prime} \\
\mathrm{cm}^{3} \mathrm{~mol}^{-1} \mathrm{~s}^{-1}\end{array}$ \\
\hline Low $A$ fit & 0 & $2.3 \times 10^{11}$ & 32 & $6.1 \times 10^{9}$ \\
High $A$ fit & 0 & $1.1 \times 10^{13}$ & 64 & $7.3 \times 10^{9}$ \\
\hline Low $A$ fit & $\frac{1}{2}$ & $2.1 \times 10^{15}$ & 40 & $6.9 \times 10^{9}$ \\
High $A$ fit & $\frac{1}{2}$ & $2.7 \times 10^{15}$ & 43 & $6.4 \times 10^{9}$ \\
\hline Low $A$ fit & 1 & $2.1 \times 10^{18}$ & 30 & $6.8 \times 10^{9}$ \\
High $A$ fit & 1 & $2.1 \times 10^{19}$ & 50 & $6.9 \times 10^{9}$ \\
\hline
\end{tabular}

The fitted activation energies, $50 \pm 20 \mathrm{~kJ} / \mathrm{mol}$, are similar to those from the theoretically calculated rates, $55 \pm 25 \mathrm{~kJ} / \mathrm{mol}$, in Section 3.2 .3 . There is a factor of 10 difference in $k_{\text {fit }}^{\prime}$, between the limiting cases in Table 3 when extrapolated to $2000 \mathrm{~K}$. These extremes are $1 / 2$ and 5 times the Ghoshtagore [9] rate at $2000 \mathrm{~K}$. Since oxygen is in five fold excess similar fits are achieved with $m=0,1 / 2,1$. Conclusions about the relative order with respect to oxygen can not be made based on this data.

The optimisation was performed against a subset of all the data available in the paper by Pratsinis et al. [40]. We present the best estimate of the $\mathrm{TiCl}_{4}$ adsorption kinetics based on the combination of the DFT studies and the data available to us. Future work should aim to refine the rates of $\mathrm{TiCl}_{4}$ adsorption and the $\mathrm{O}_{2}$ adsorption step using the data from Pratsinis et al. [40] at various $\mathrm{TiCl}_{4} / \mathrm{O}_{2}$ ratios, and to further investigate the interaction between 
these aspects of the model and the form and rate of inception. Using more experimental data and refining the particle model would allow one to further test the hypotheses presented here and reduce the large error bounds on the kinetic parameters.

\subsection{Recommended model}

Building on these new fits and the restrictions on the form suggested by the theoretical investigations, we suggest a kinetic model for future simulations in Table 4. This shows the Eley-Rideal kinetic model in which the $\mathrm{TiCl}_{4}$ adsorption rate is set to give growth rates equal to the fitted reactions in Table 3. The secondary $\mathrm{O}_{2}$ reaction is given the collision limited rate multiplied by an exponential sticking probability using the activation energy measured by Smith et al. [15]. This step is considerably faster than the rate limiting $\mathrm{TiCl}_{4}$ adsorption step. At stoichiometric concentrations, coverage of $\mathrm{S}^{*}$ is over $98 \%$ at the quasi-steady state, and the model behaves like a one step model. Only at low $\mathrm{O}_{2}$ concentration does the coverage of $\mathrm{TiCl}_{4}{ }^{*}$ become appreciable. This goes some way to explain the non linear dependence on oxygen concentration. Further insight into the pre-exponential factor for the $\mathrm{O}_{2}$ adsorption step would allow the model to be applicable in the full range of $\mathrm{TiCl}_{4} / \mathrm{O}_{2}$ concentration regimes.

Table 4: The recommended kinetic model with a $\mathrm{TiCl}_{4}$ adsorption rate found by fitting the overall surface growth rate to Pratsinis et al. [40]. (g) and (s) signify gas, and solid phases respectively. $\mathrm{S}^{*}$ is used to represent a generic reactive surface site, $\mathrm{TiCl}_{4}{ }^{*}$ represents adsorbed $\mathrm{TiCl}_{4}$. Rate constants are calculated based on $100 \%$ coverage of reactive sites and a surface site density

of $9.43 \times 10^{-10} \mathrm{~mol} \mathrm{~cm}^{-2}$. The model is available in Cantera format [45] as Supporting Information.

\begin{tabular}{llccc}
\hline & & \multicolumn{3}{c}{$k=A T^{n} \exp \left(-E_{\mathrm{a}} / k_{\mathrm{B}} T\right)$} \\
\cline { 3 - 5 }$\#$ & Reaction & $\begin{array}{c}A \\
\mathrm{~cm}^{3} \mathrm{~mol}^{-1} \mathrm{~s}^{-1}\end{array}$ & $\begin{array}{c}E_{\mathrm{a}} \\
\mathrm{kJ} / \mathrm{mol}\end{array}$ \\
\hline 1 & $\mathrm{TiCl}_{4}(\mathrm{~g})+\mathrm{S}^{*} \stackrel{k_{1}}{\longrightarrow} \mathrm{TiCl}_{4}{ }^{*}$ & $2.1 \times 10^{12}$ & 0 & 50 \\
2 & $\mathrm{TiCl}_{4}{ }^{*}+\mathrm{O}_{2}(\mathrm{~g}) \stackrel{k_{2}}{\longrightarrow} \mathrm{TiO}_{2}(\mathrm{~s})+2 \mathrm{Cl}_{2}(\mathrm{~g})+\mathrm{S}^{*}$ & $6.8 \times 10^{11}$ & $\frac{1}{2}$ & 25 \\
\hline
\end{tabular}


Table 3 demonstrates that the data can be fitted using many $A / E_{\mathrm{a}}$ combinations. The particular fit was chosen so as to have an activation energy that was central to the range given in Table 3. Table 4 shows the Arrhenius parameters we present based on assuming $100 \%$ coverage of reactive sites and a surface site density of $9.43 \times 10^{-10} \mathrm{~mol} \mathrm{~cm}^{-2}$. Obviously, if further insight into the coverage of oxygen vacancies becomes available the fitted rates must be adjusted accordingly. Given the wide range of Arrhenius parameters that gave good fits the recommended rate is only valid in this temperature range.

The multiscale model is highly non-linear and it is difficult to ascertain rates of individual processes using optimisation techniques. This is a critical issue for the community to resolve because the relative rates of gas kinetics, inception, and surface growth determine particle properties such as the particle size distribution. More work needs to be done to understand the relative rates of all the processes involved. While these parameter fitting studies do not provide a fine degree of accuracy, they are useful for investigating the relative rates of important processes and highlight the incompatibility between the surface growth rate of Ghoshtagore [9], the reaction rates of Herzler and Roth [39], and the inception model of West et al. [10]. The main conclusions of this section are:

- The fitted activation energy for $\mathrm{TiCl}_{4}$ adsorption is $50 \pm 20 \mathrm{~kJ} / \mathrm{mol}$. The pre-exponential factor is $2.1 \times 10^{12} \mathrm{~cm}^{3} \mathrm{~mol}^{-1} \mathrm{~s}^{-1}$ to within a factor of ten.

- We can not fit the rate of oxygen adsorption based on the data in this paper. We therefore assume a collision limited reaction with an exponential sticking probability based on the experimental investigation of Smith et al. [15].

- For future simulations, we recommend the kinetic model for surface growth shown in Table 4.

\section{Conclusions}

We have presented a density functional theory study into the adsorption of $\mathrm{TiCl}_{4}$ on the $\left[\begin{array}{lll}1 & 1 & 0\end{array}\right]$ surface of rutile $\mathrm{TiO}_{2}$. Based on these results and previous experimental observations, we suggest a new kinetic model for surface growth. This model reflects atomistic processes and behaves in subtle but crucially different ways to previous phenomenological models. We simulated a plug 
flow reactor experiment from the literature using the moment method with interpolative closure to solve the particle population balance and couple it to the gas kinetic model. A parameter optimisation procedure allowed us to recommend a rate for the $\mathrm{TiCl}_{4}$ adsorption reaction in the new model. It was not possible to locate unique values for the Arrhenius parameters leaving temperature dependence of the rate as a significant area for future work. This work leads to the following conclusions:

- The adsorption energy of $\mathrm{TiCl}_{4}$ onto a bridging oxygen vacancy is $-117 \mathrm{~kJ} / \mathrm{mol}$, with an energy barrier of $25 \mathrm{~kJ} / \mathrm{mol}$. The rate of this adsorption was calculated using transition state theory with estimated vibrational frequencies.

- Comparisons between previous and possible surface growth models indicate that an Eley-Rideal model with $\mathrm{TiCl}_{4}$ adsorption first is appropriate.

- The surface growth of $\mathrm{TiO}_{2}$ can be explained using an Eley-Rideal model, with a $\mathrm{TiCl}_{4}$ adsorption rate fitted to experiment. The activation energy for this $\mathrm{TiCl}_{4}$ adsorption process is $50 \pm 20 \mathrm{~kJ} / \mathrm{mol}$. This new model incorporates a physically reasonable dependence on both $\mathrm{O}_{2}$ and $\mathrm{TiCl}_{4}$ concentrations when coupled to the existing gas kinetic model. 


\section{Acknowledgements}

We thank Tioxide Europe Limited for the financial support of Raphael Shirley and Luke Miller, reSolutions Ltd and the EPSRC (EP/C537564/1) for the financial support of Jethro Akroyd, and the Martin Smith Foundation for the financial support of Oliver Inderwildi. We thank Heidelberg University

for providing generous access to the HELICS high performance computing system. 


\section{References}

[1] J. Emsley, Molecules at an Exhibition, Oxford University Press, 1999.

[2] R. A. Gonzalez, C. D. Musick, J. N. Tilton, Process for controlling agglomeration in the manufacture of $\mathrm{TiO}_{2}$, US Patent 5,508,015, 1996.

[3] J. C. Deberry, M. Robinson, M. Pomponi, A. J. Beach, Y. Xiong, K. Akhtar, Controlled vapor phase oxidation of titanium tetrachloride to manufacture titanium dioxide, US Patent 6,387,347, 2002.

[4] S. E. Pratsinis, P. T. Spicer, Chemical Engineering Science 53 (1998) 1861-1868.

[5] P. T. Spicer, O. Chaoul, S. Tsantilis, S. E. Pratsinis, Journal of Aerosol Science 33 (2002) 17-34.

[6] S. Tsantilis, S. E. Pratsinis, Journal of Aerosol Science 35 (2004) 405420.

[7] N. M. Morgan, C. G. Wells, M. J. Goodson, M. Kraft, W. Wagner, Journal of Computational Physics 211 (2006) 638-658.

[8] R. H. West, M. S. Celnik, O. R. Inderwildi, M. Kraft, G. J. O. Beran, W. H. Green, Industrial Engineering Chemistry Research 46 (2007) 6147-6156.

[9] R. N. Ghoshtagore, Journal of the Electrochemical Society 117 (1970) $529-534$.

[10] R. H. West, R. Shirley, M. Kraft, C. F. Goldsmith, W. H. Green, Combustion and Flame 156 (2009) 1764-1770.

[11] R. Shirley, M. Kraft, O. R. Inderwildi, Physical Review B 81 (2010) 075111.

[12] T. S. Totton, R. Shirley, M. Kraft, Proceedings of the Combustion Institute 33 (2011) 493-500.

[13] R. Shirley, Y. Liu, T. S. Totton, R. H. West, M. Kraft, Journal of Physical Chemistry A 113 (2009) 13790-13796. 
[14] R. Shirley, W. Phadungsukanan, M. Kraft, J. Downing, N. E. Day, P. Murray-Rust, The Journal of Physical Chemistry A 114 (2010) 1182511832.

[15] R. D. Smith, R. A. Bennett, M. Bowker, Physical Review B 66 (2002) 035409 .

[16] U. Diebold, Surface Science Reports 48 (2003) 53-229.

[17] M. Ramamoorthy, D. Vanderbilt, R. D. King-Smith, Physical Review B 49 (1994) 16721-16727.

[18] P. J. D. Lindan, N. M. Harrison, M. J. Gillan, Physical Review Letters 80 (1998) 762-765.

[19] L. A. Harris, A. A. Quong, Physical Review Letters 93 (2004) 086105.

[20] D. C. Sorescu, J. T. Yates, The Journal of Physical Chemistry B 102 (1998) 4556-4565.

[21] O. Inderwildi, M. Kraft, Chemical Physics and Physical Chemistry 8 (2007) 444-451.

[22] M. Frenklach, Chemical Engineering Science 57 (2002) 2229-2239.

[23] C. G. Wells, N. M. Morgan, M. Kraft, W. Wagner, Chemical Engineering Science 61 (2006) 158-166.

[24] M. Celnik, R. Patterson, M. Kraft, W. Wagner, Journal of Computational Physics 228 (2009) 2758-2769.

[25] M. Mehta, Y. Sung, V. Raman, R. O. Fox, Industrial \& Engineering Chemistry Research 49 (2010) 10663-10673.

[26] J. Akroyd, A. J. Smith, L. R. McGlashan, M. Kraft, Chemical Engineering Science 65 (2010) 5429-5441.

[27] J. Akroyd, A. J. Smith, L. R. McGlashan, M. Kraft, Chemical Engineering Science 65 (2010) 1915-1924.

[28] J. Akroyd, A. J. Smith, R. Shirley, L. R. McGlashan, M. Kraft, Chemical Engineering Science (2011) in press. 
[29] S. Clark, M. Segall, C. Pickard, P. Hasnip, M. Probert, K. Refson, M. Payne, Zeitschrift Fur Kristallographie 220 (2005) 567-570.

[30] J. Perdew, K. Burke, M. Ernzerhof, Physical Review Letters 77 (1996) 3865-3868.

[31] D. Vanderbilt, Physics Review B 41 (1990) 7892-7895.

[32] A. Kiejna, T. Pabisiak, S. Gao, Journal of Physics: Condensed matter 18 (2006) 4207-4217.

[33] H. J. Monkhorst, J. D. Pack, Physical Review B 13 (1976) 5188-5192.

[34] K. J. Hameeuw, G. Cantele, D. Ninno, F. Trani, G. Iadonisi, The Journal of Chemical Physics 124 (2006) 024708.

[35] M. V. Ganduglia-Pirovano, A. Hofmann, J. Sauer, Surface Science Reports 62 (2007) 219-270.

[36] R. Schaub, P. Thostrup, N. Lopez, E. Lægsgaard, I. Stensgaard, J. K. Nørskov, F. Besenbacher, Physical Review Letters 87 (2001) 266104.

[37] S. Wendt, R. Schaub, J. Matthiesen, E. Vestergaard, E. Wahlstrm, M. Rasmussen, P. Thostrup, L. Molina, E. Lgsgaard, I. Stensgaard, B. Hammer, F. Besenbacher, Surface Science 598 (2005) 226-245.

[38] R. A. van Santen, J. W. Niemantsverdriet, Chemical kinetics and catalysis, Plenum Press, 1995.

[39] J. Herzler, P. Roth, Journal of Physical Chemistry A 101 (1997) 93419343.

[40] S. E. Pratsinis, H. Bai, P. Biswas, M. Frenklach, S. V. R. Mastrangelo, Journal of the American Ceramic Society 73 (1990) 2158-2162.

[41] N. Govind, M. Petersen, G. Fitzgerald, D. King-Smith, J. Andzelm, Computational Materials Science 28 (2003) 250-258. Proceedings of the Symposium on Software Development for Process and Materials Design.

[42] P. W. Atkins, Physical Chemistry, Oxford University Press, 1998.

[43] R. H. West, G. J. O. Beran, W. H. Green, M. Kraft, Journal of Physical Chemistry A 111 (2007) 3560-3565. 
[44] M. Rasmussen, L. Molina, B. Hammer, Journal of Chemical Physics 120 (2004) 988-997.

[45] D. G. Goodwin, in: M. Allendorff, F. Maury, F. Teyssandier (Eds.), Chemical Vapor Deposition XVI and EUROCVD 14, volume 2003-08 of ECS Proceedings, The Electrochemical Society, The Electrochemical Society, Pennington, New Jersey, USA, 2003, pp. 155-162.

[46] O. Deutschmann, Computational Fluid Dynamics Simulation of Catalytic Reactors, Wiley, 2008.

[47] R. Raghavan, Measurement of the High-Temperature Kinetics of Titanium Tetrachloride $\left(\mathrm{TiCl}_{4}\right)$ Reactions in a Rapid Compression Machine, Ph.D. thesis, Case Western Reserve University, http://www.case.edu/cse/eche/people/students/theses/RaghavanRamPhD.pdf, 2001. 
Click here to download Supplementary Material: adsorbed.castep

Output file
Click here t

Click here to download Supplementary Material: adsorbed.castep

Click here to download Supplementary Material: adsorbed.castep

Click here to download supplementary Material: adsorbedicastep

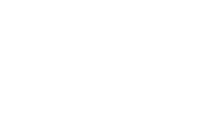
(1) (1) (1) (1) (1) . . . .

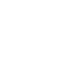

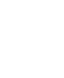

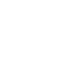
- n

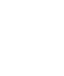

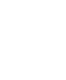

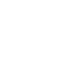

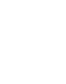

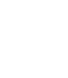

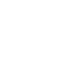

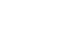


Click here to download Supplementary Material: desorbed.castep

Output file
Click here t

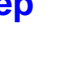

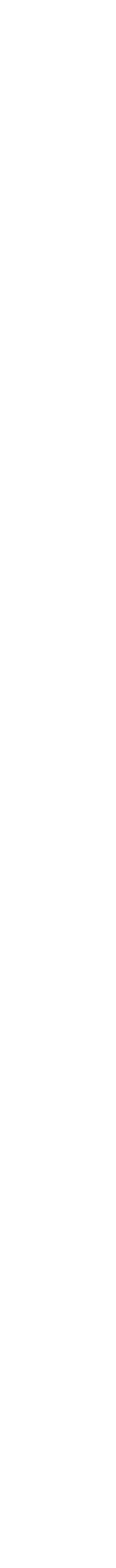


Click here to download Supplementary Material: gas.cti .

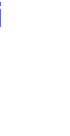

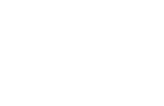
(1) (1) (1) (1)

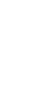
(1) (1) (1) (n)

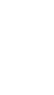
(n)

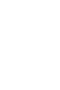

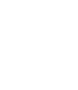

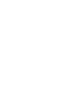
(n) i , , , . . . .

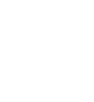

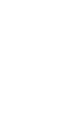

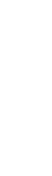

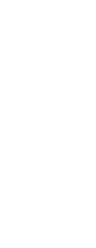

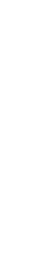
.

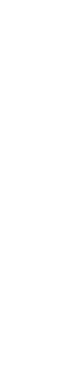

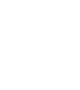
(

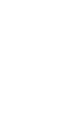
列

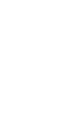

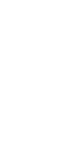

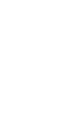

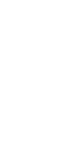


Click here to download Supplementary Material: surface.cti

Output file
Click here $t$

entary Material: surface.cti

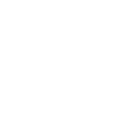

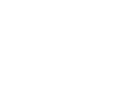

(1)

(1)

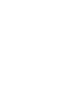
(1) $\sqrt{2}$ (1)

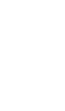
(1) . . . res

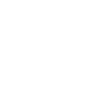
.

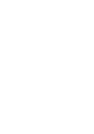
.

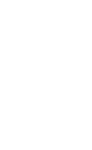

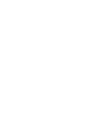

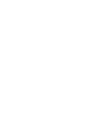

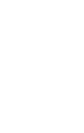

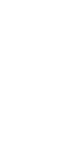

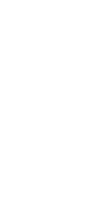

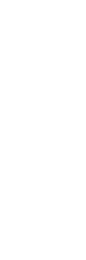
. 
Output file
Click here to download Supplementary Material: transitionState.castep Click here to download Supplementary Material: transitionstatecastep

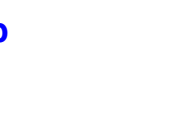

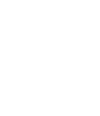
(1) (1) (1) (1) (1) (1)

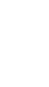
(1)

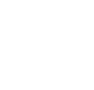

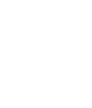

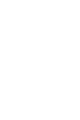

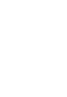
. . . . ( (1) (2)

(1) (1) (1) . 